LAWRENCE LIVERMORE N A T IO N A L LABORATORY

\title{
Computational Engineering of the Stability and Optical Gaps of SiC Quantum Dots
}

F. Reboredo, L. Pizzagalli, G. Galli

March 18, 2004

APS March Meeting

Montreal, Canada

March 22, 2004 through March 26, 2004 
This document was prepared as an account of work sponsored by an agency of the United States Government. Neither the United States Government nor the University of California nor any of their employees, makes any warranty, express or implied, or assumes any legal liability or responsibility for the accuracy, completeness, or usefulness of any information, apparatus, product, or process disclosed, or represents that its use would not infringe privately owned rights. Reference herein to any specific commercial product, process, or service by trade name, trademark, manufacturer, or otherwise, does not necessarily constitute or imply its endorsement, recommendation, or favoring by the United States Government or the University of California. The views and opinions of authors expressed herein do not necessarily state or reflect those of the United States Government or the University of California, and shall not be used for advertising or product endorsement purposes. 


\section{Computational engineering of the stability and optical gaps of SiC quantum dots}

Fernando A. Reboredo*, Laurent Pizzagalli§ and Giulia Galli*

*Lawrence Livermore National Laboratory, Livermore CA USA

sUniversité de Poitiers, Cedex France

Si $O$
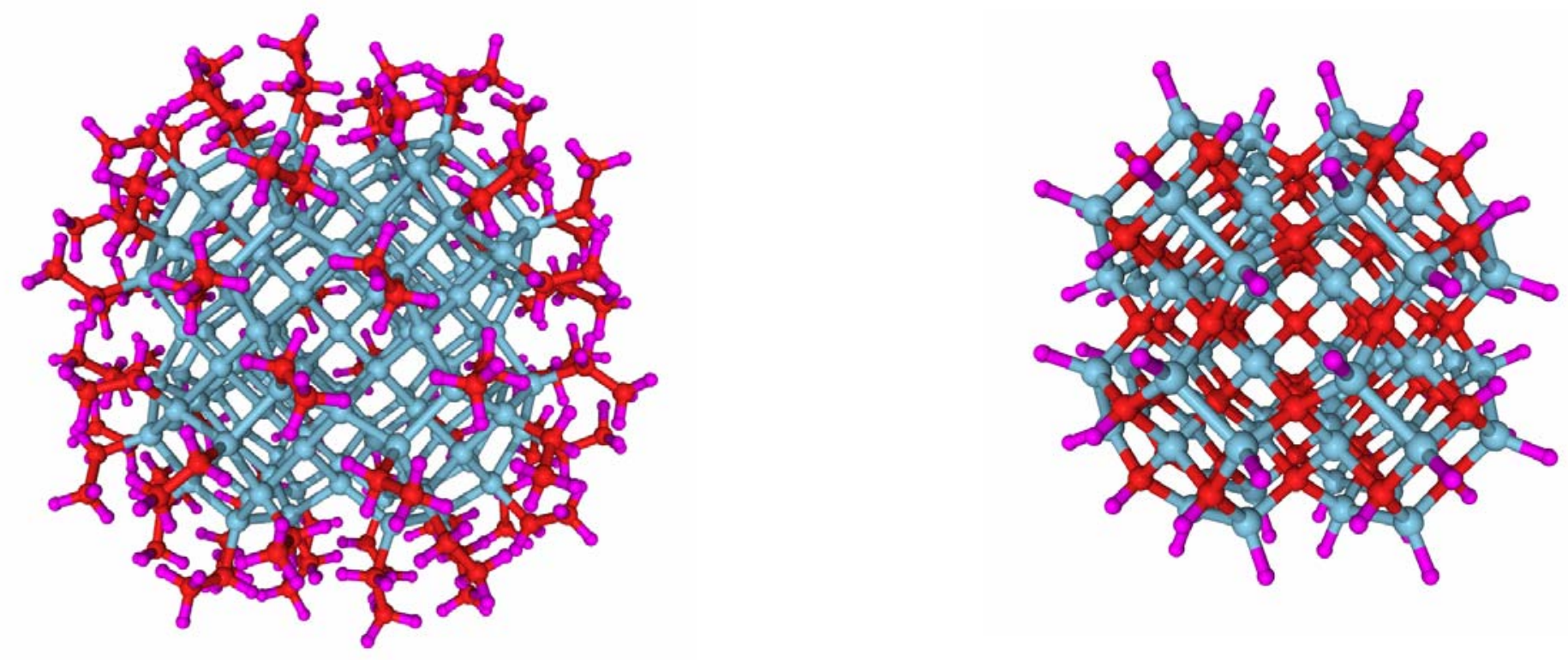

$\mathrm{Si}_{142}\left(\mathrm{C}_{2} \mathrm{H}_{5}\right)_{72}$

$\mathrm{Si}_{80} \mathrm{C}_{62} \mathrm{H}_{72}$ 


\section{Why SiC quantum dots?}
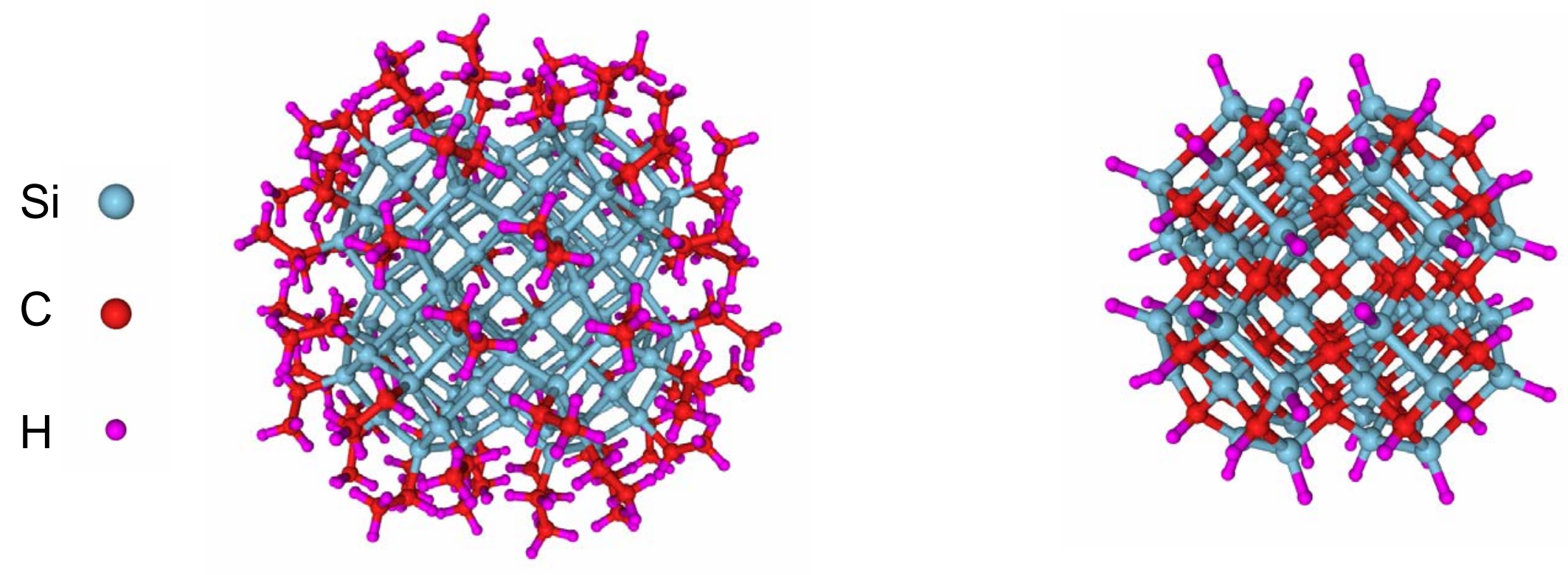

$\mathrm{Si}_{142}\left(\mathrm{C}_{2} \mathrm{H}_{5}\right)_{72}$

$\mathrm{Si}_{80} \mathrm{C}_{62} \mathrm{H}_{72}$ 


\section{Different Surface structures}

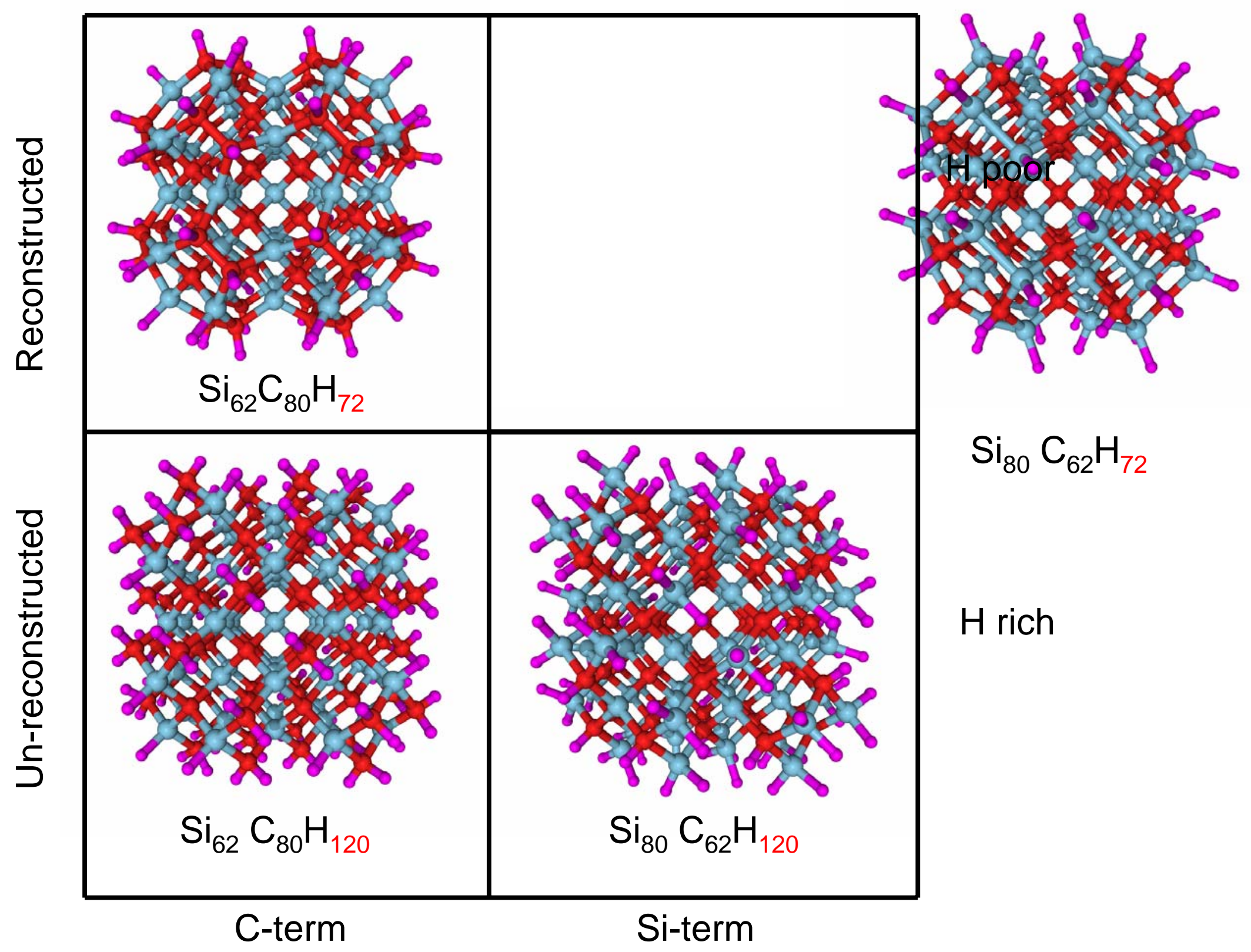




\section{Different Surface structures}

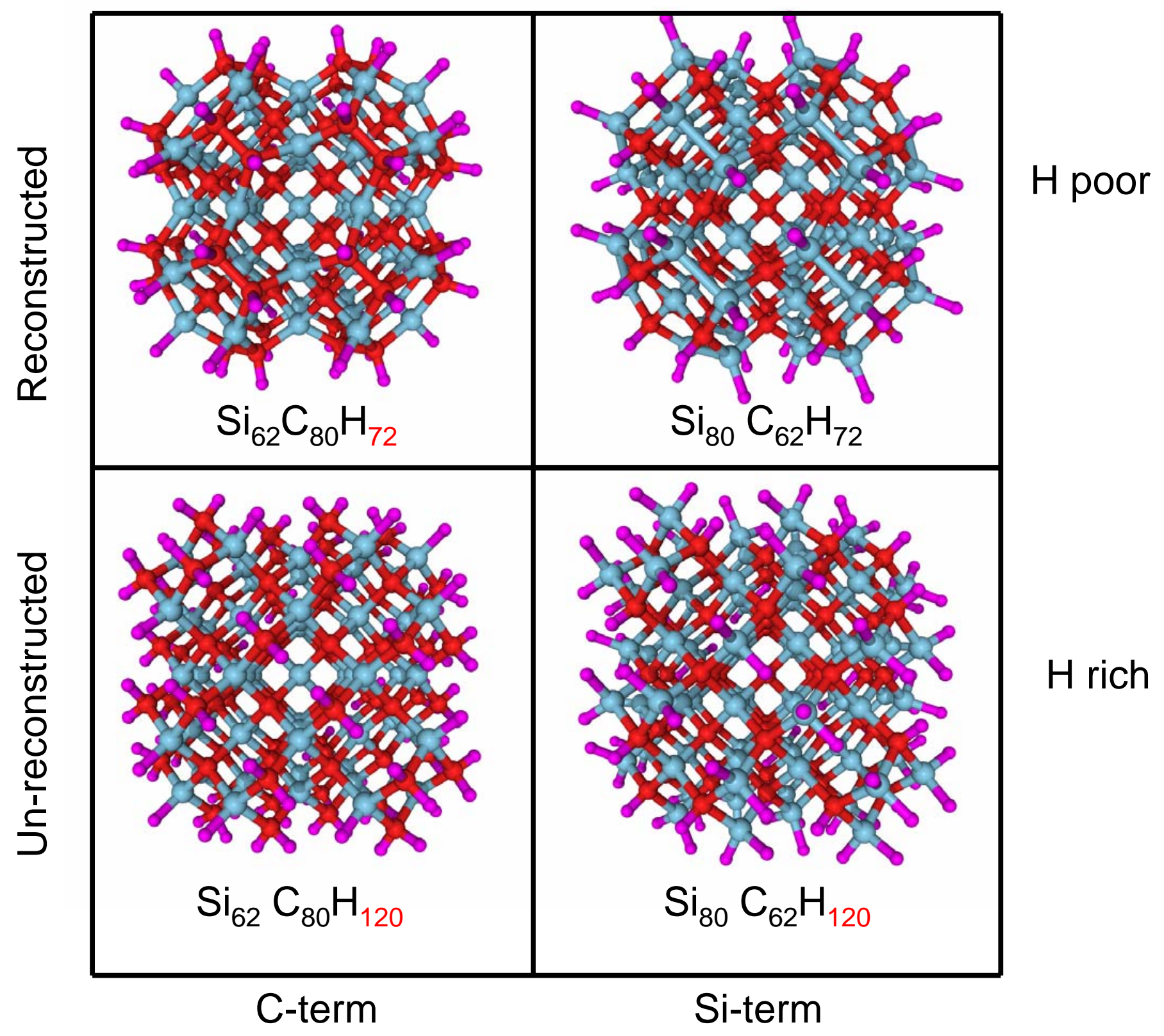




\section{Different Surface structures}

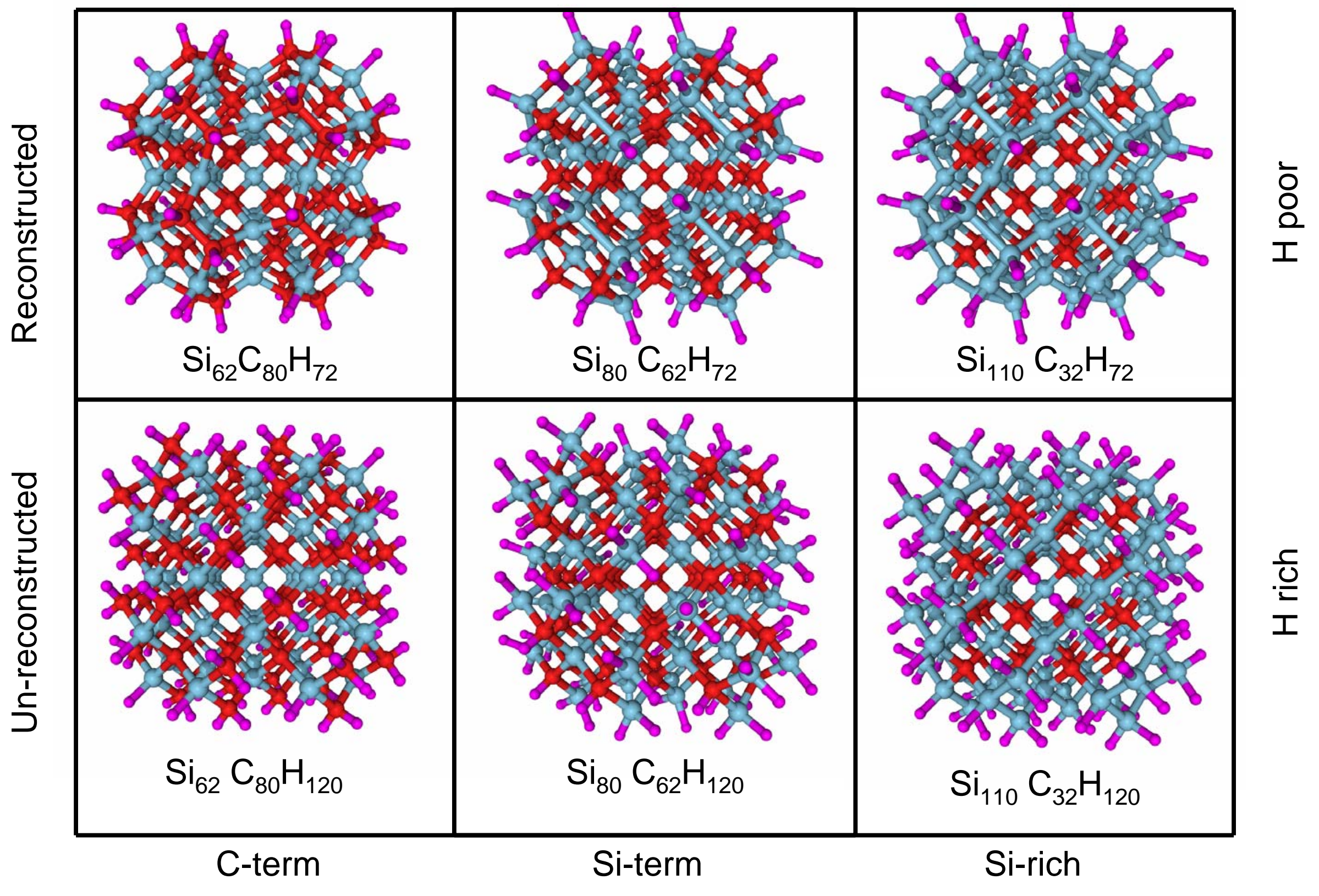




\section{Size dependence for all this structures!}

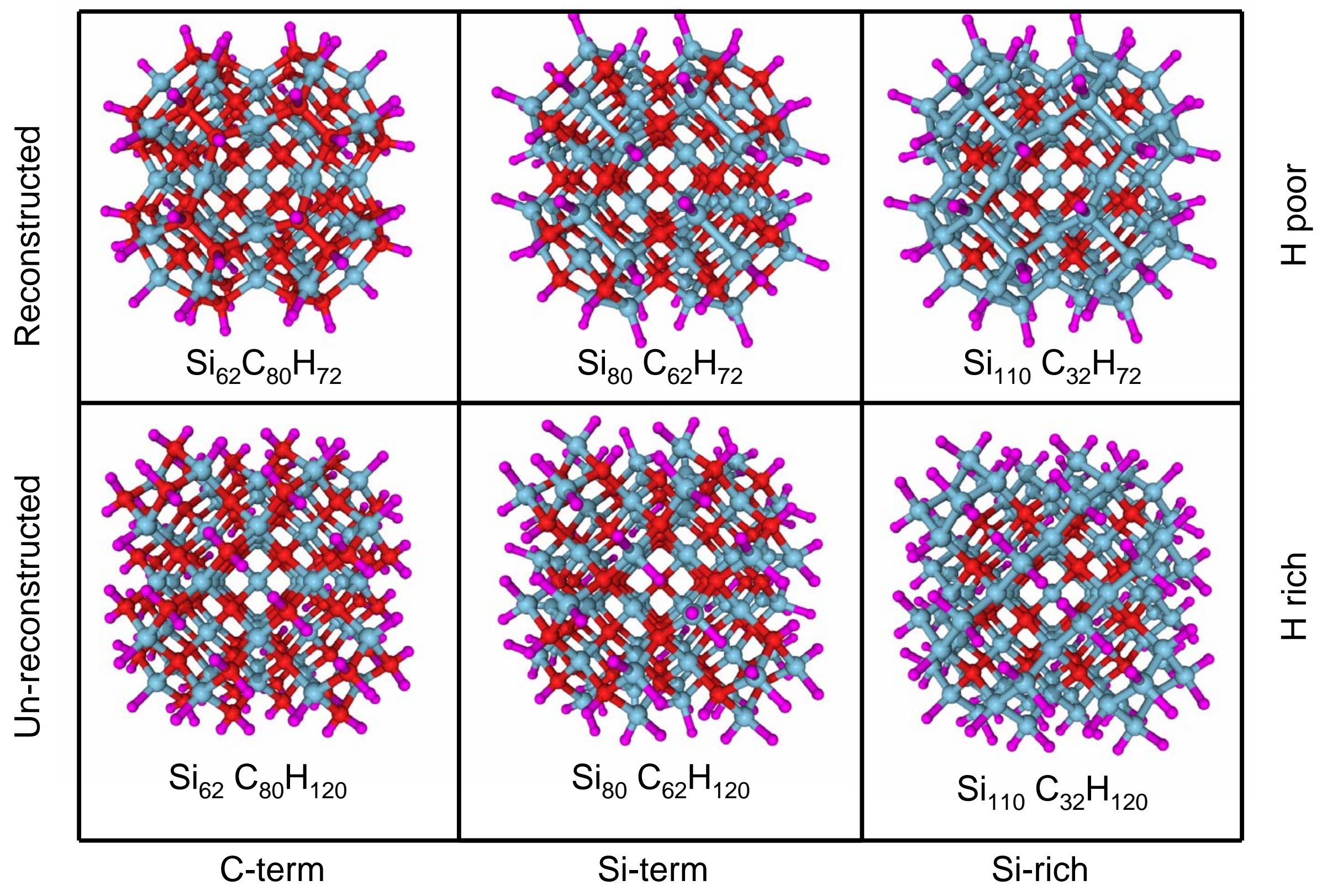




\section{Single particle gap of SiC QD as a funtion of size and surface structure}

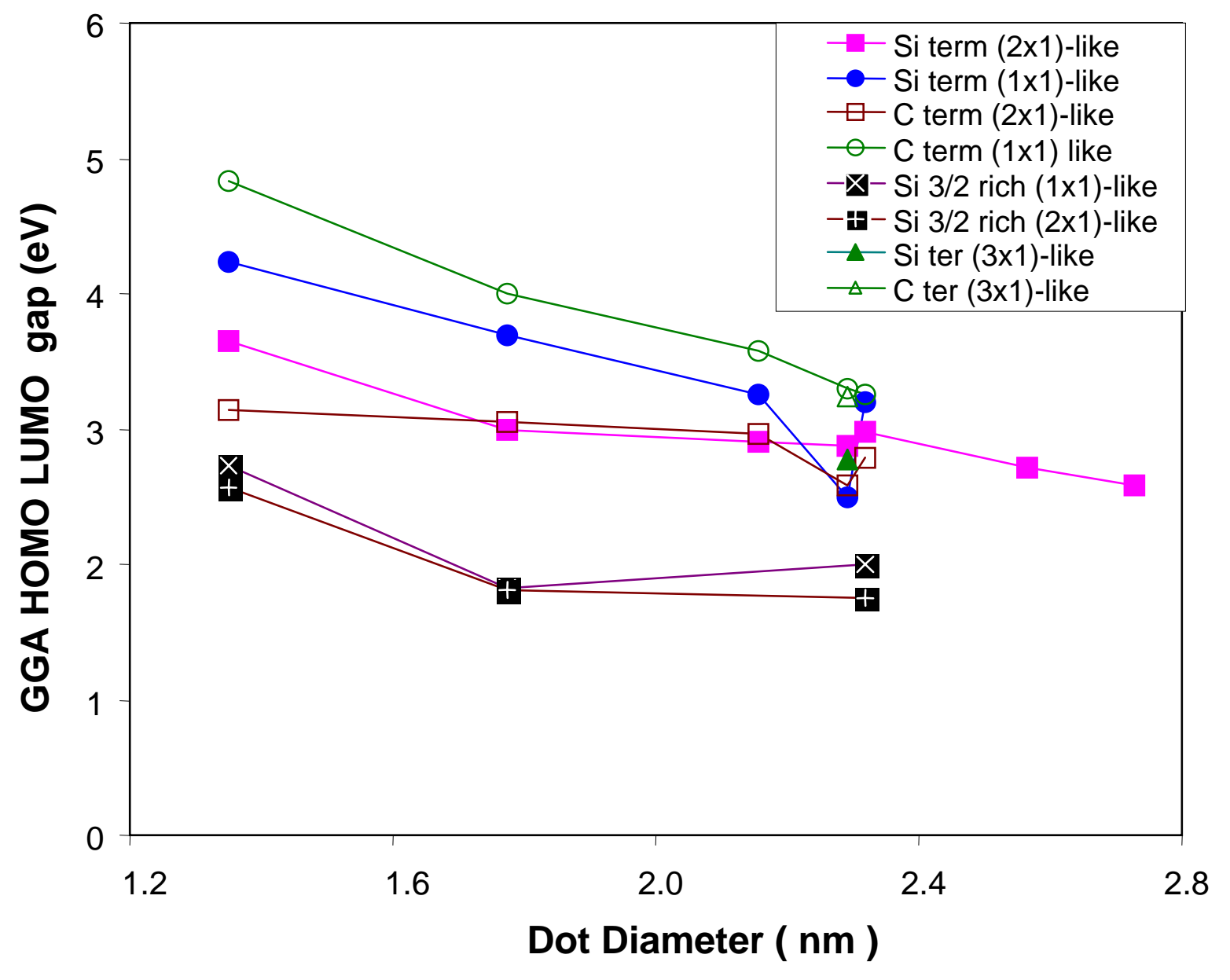

The surface structure is as important as the size as a determiner of the gap 


\section{SiC QDs: Surface phase diagram under equilibrium}

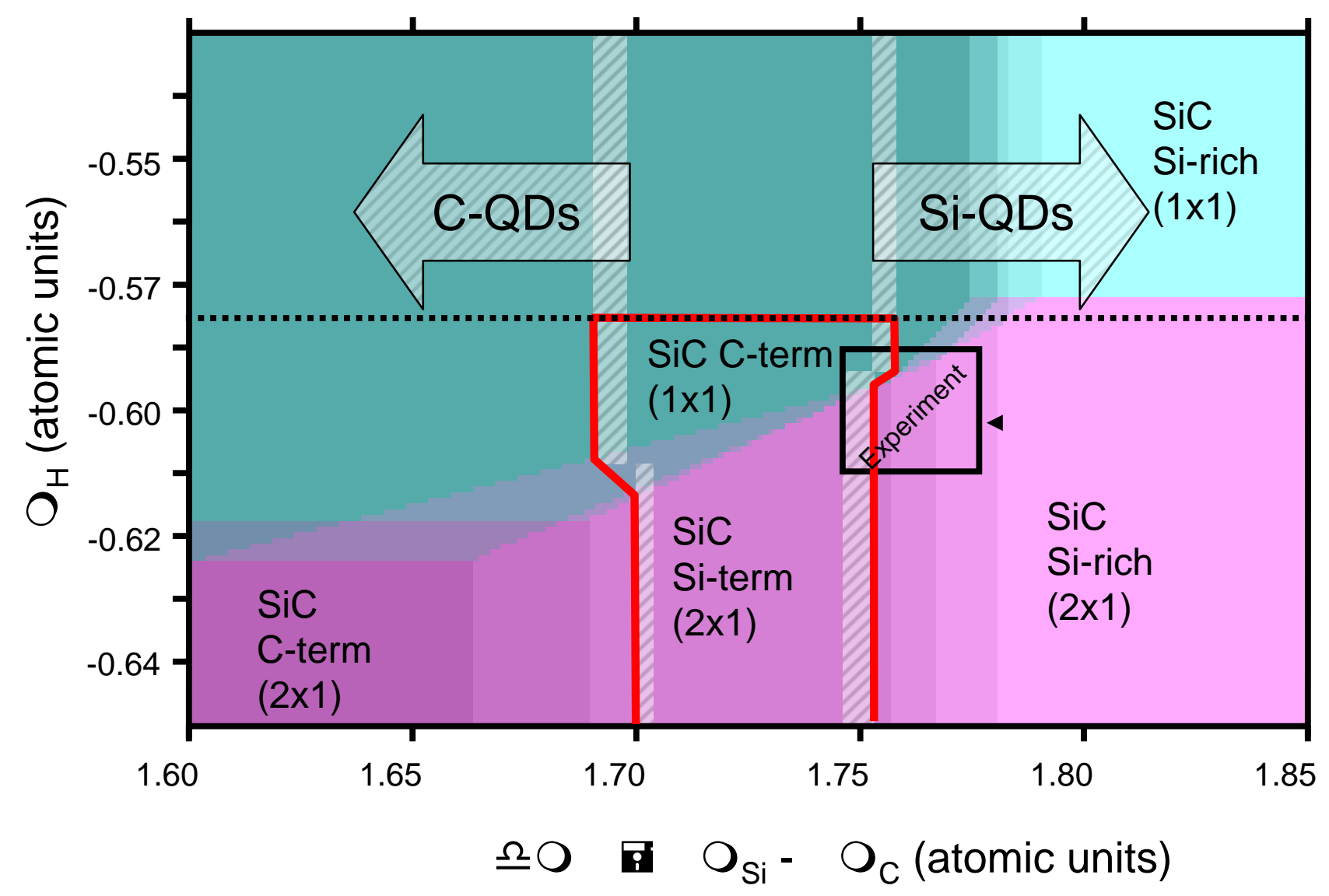

Only three types of surfaces are in principle possible at or near equilibrium. 


\section{Only two surfaces are stable}

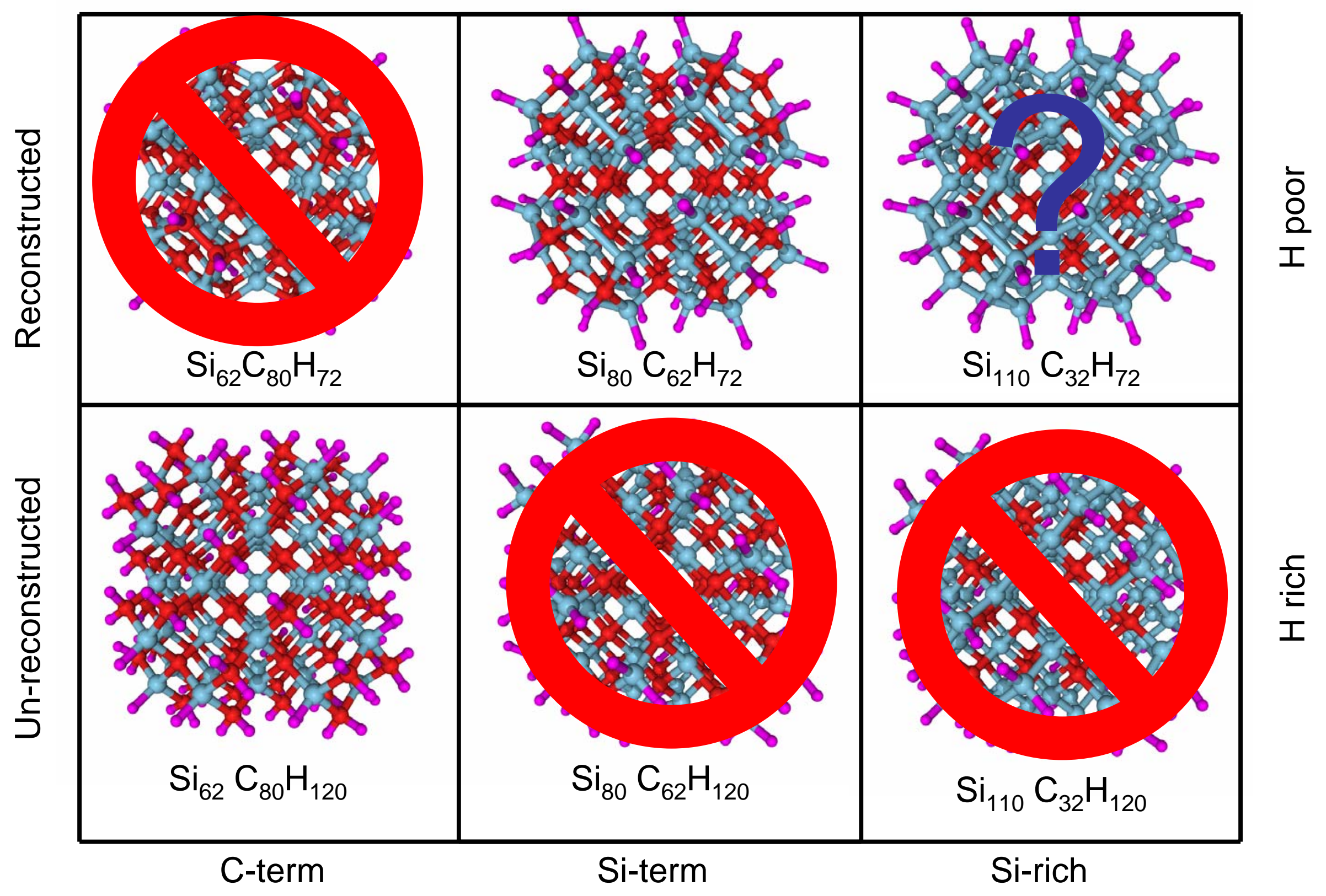


Single particle gap of SiC QDs as a funtion of size and surface structure

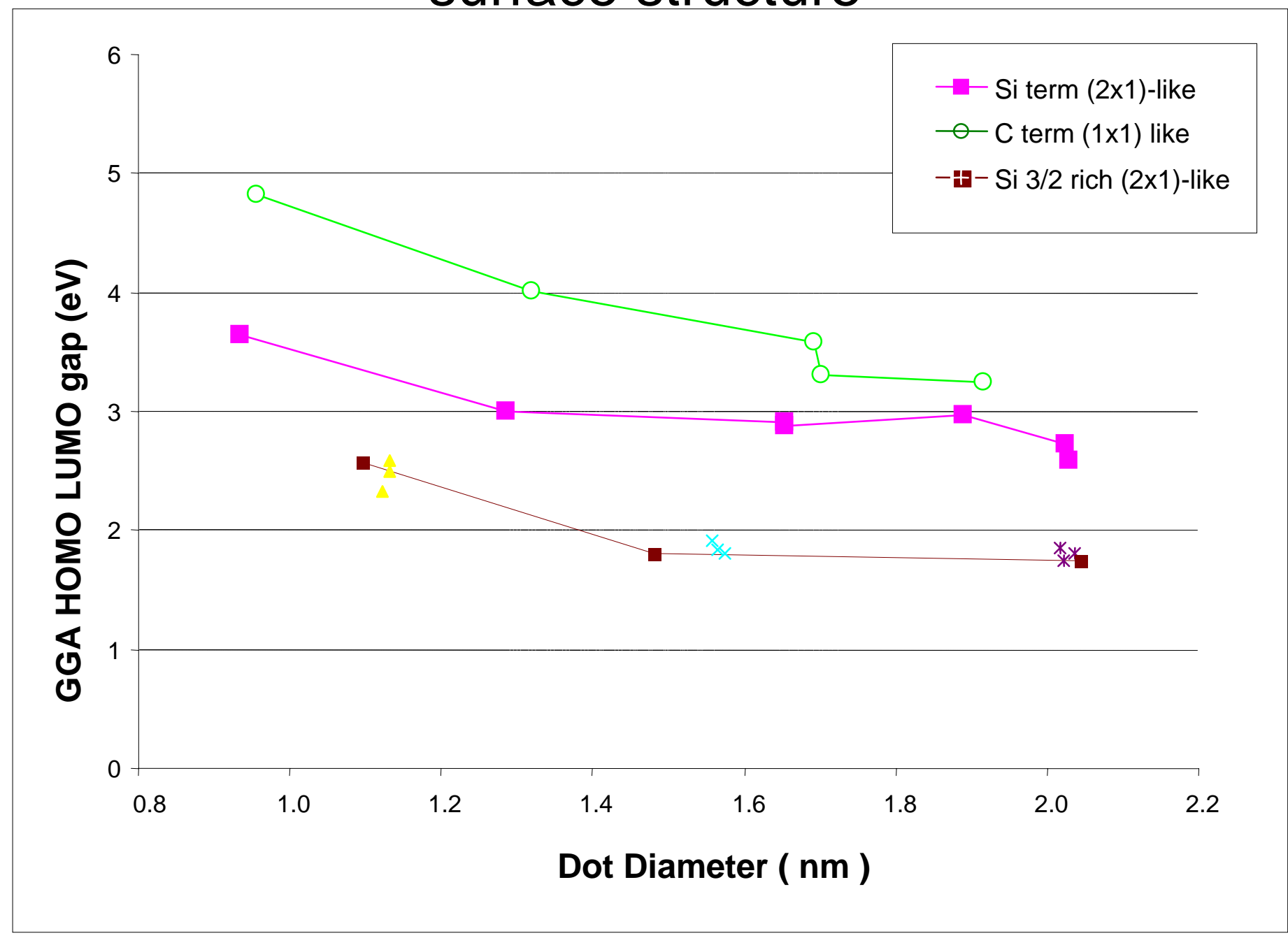

Only three types of surfaces are in principle possible near equilibrium. 


\section{Localization of band edge wave functions}

Si Qdots

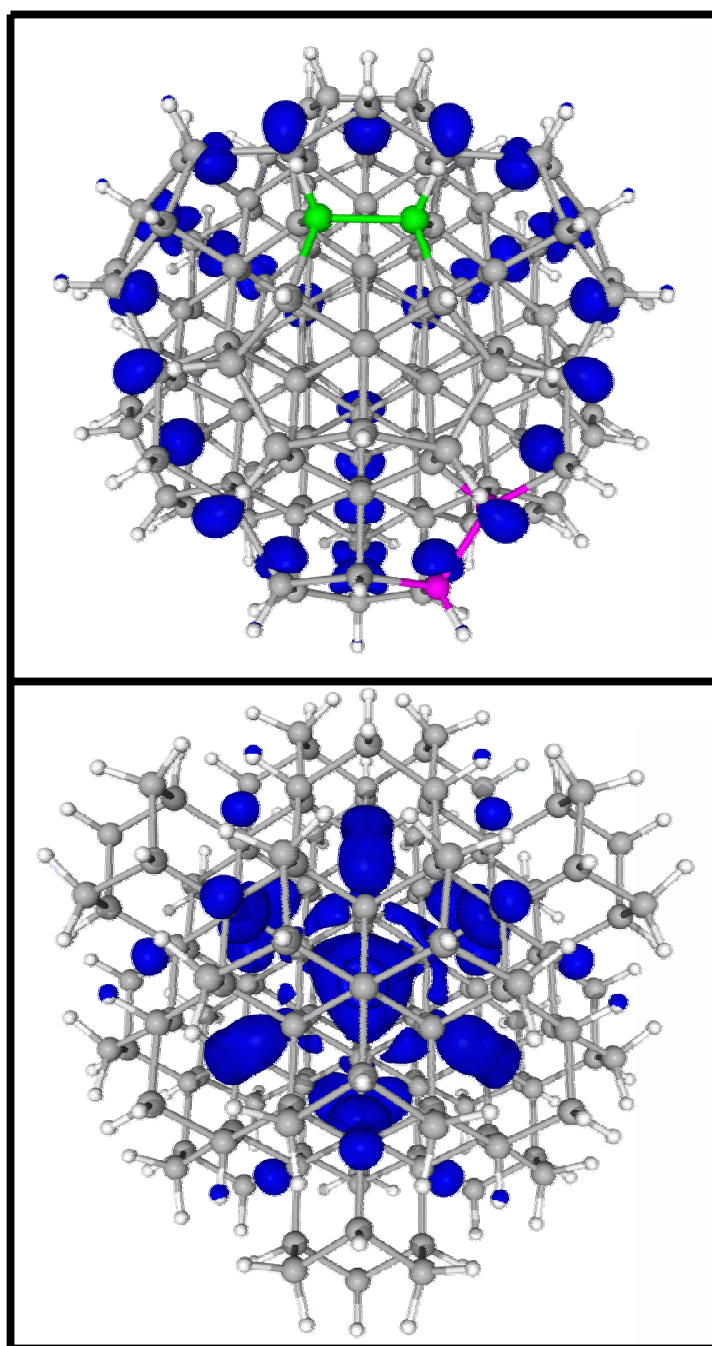

SiC Qdots
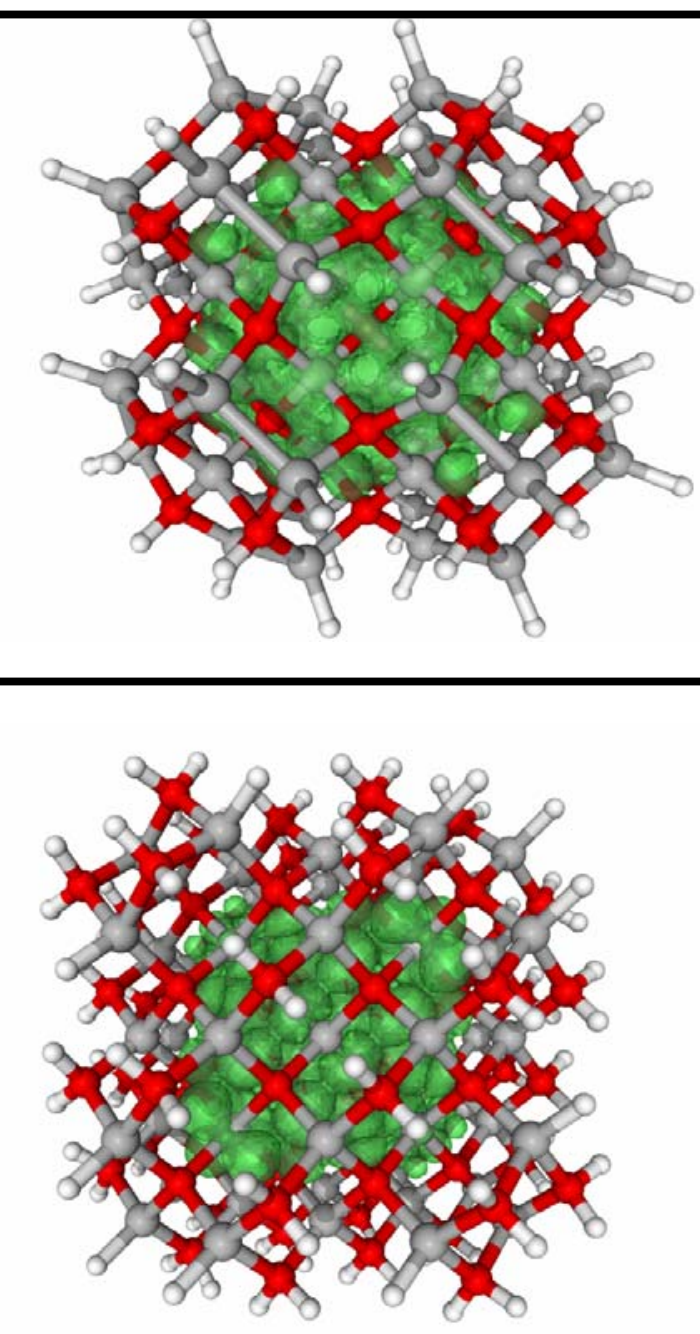

(Si-term reconstructed)

(C-term Un -reconstructed)

In SiC surface-induced strain and not surface localization originate large gap differences 


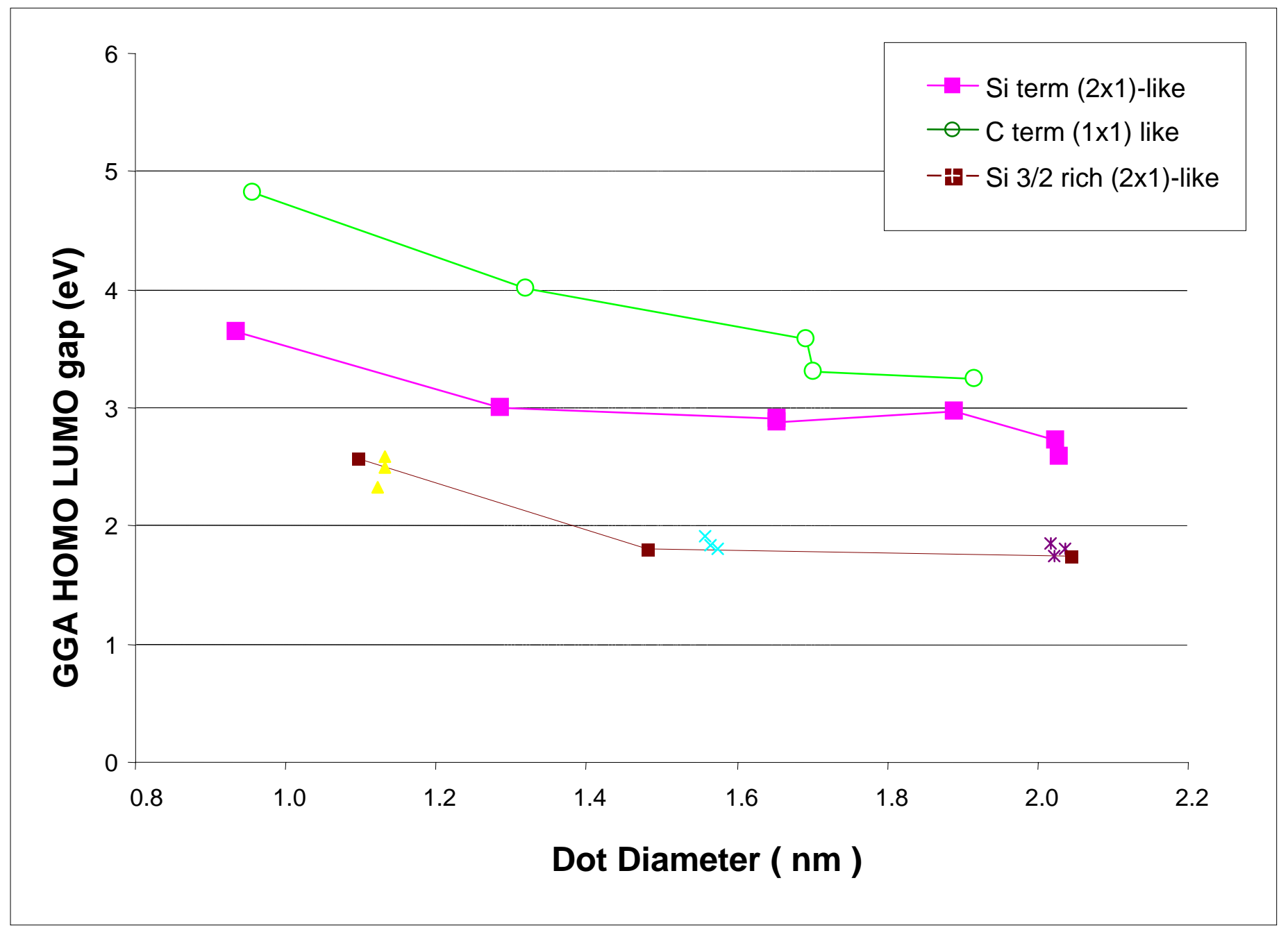




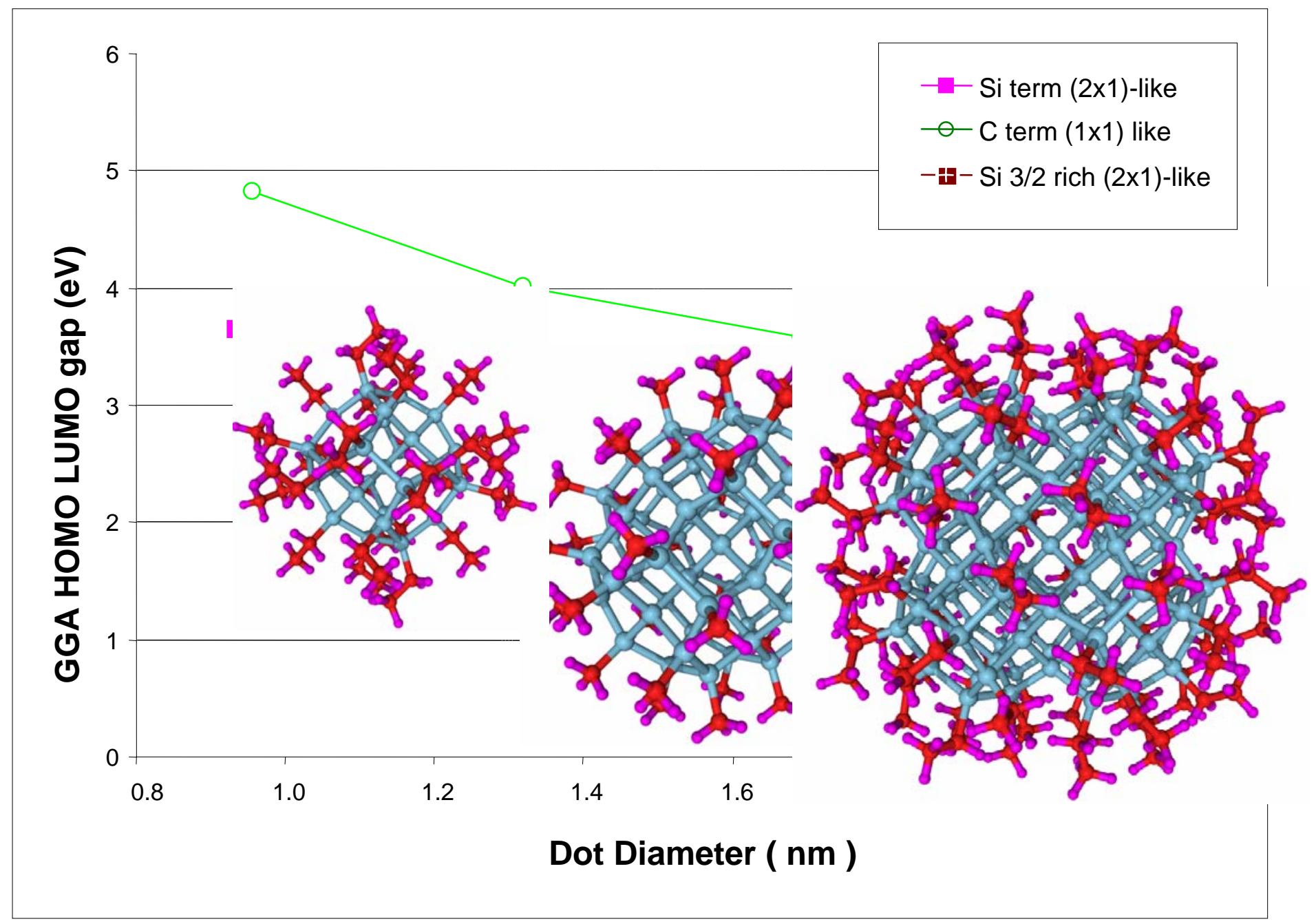




\section{Conclusions}

- In SiC QDs surface composition and structure are as important as size for the optical gap

- Two surfaces are possible near equilibrium; one is close

- Different experimental conditions quite different optical gaps

- C-term H-rich SiC QDs have the largest gaps in group IV

- Si-enriched SiC QDs have similar gaps than reconstructed alkyl terminated pure Si dots.

This work was performed under the auspices of the U.S. Department of Energy by University of California Lawrence Livermore National Laboratory under contract No. W-7405-Eng-48. 